九州大学学術情報リポジトリ

Kyushu University Institutional Repository

\title{
Advancing the human experience with interactive evolutionary computation
}

\section{高木，英行}

Kyushu Institute of Design

ht tp://hdl. hand le. net/2324/4486290

出版情報: SMCia/01. Proceedings of the 2001 IEEE Mountain Workshop on Soft Computing in Industrial Applications, pp. 133-134, 2001-06-27. IEEE

バージョン:

権利関係 : $\odot 2000$ IEEE. Personal use of this material is permitted. Permission from IEEE must be obtained for all other uses, in any current or future media, including reprinting/republishing this material for advertising or promotional purposes, creating new collective works, for resale or redistribution to servers or lists, or reuse of any copyrighted component of this work in other works. 


\title{
Advancing the Human Experience with Interactive Evolutionary Computation
}

\author{
Hideyuki Takagi \\ Kyushu Institute of Design \\ 4-9-1, Shiobaru, Minami-ku, Fukuoka 815-8540, Japan \\ Tel\&Fax: +81-92-553-4555, E-mail: takagi@kyushu-id.ac.jp, URL: http:// www.kyushu-id.ac.jp/ ${ }^{\sim}$ takagi/
}

\begin{abstract}
We first overview the research trend of computational intelligence, discuss what comes next in the computational intelligence research, and conclude that humanized technologies would be one of the essential keywords of the possible research direction. Then, we take up interactive evolutionary computation (IEC) as one of the humanized technologies and show how IEC technology has spread to a wide variety of fields, what problems remain, and what kinds of challenges need to be solved, and how to make the technology practical.
\end{abstract}

\section{INTRODUCTION}

Looking back over the history of computational intelligence in the 20th century, especially that of socalled Soft Computing. The seeds of the neural networks, fuzzy systems, and EC were sown in the 1960 s, and they were widely but independently researched during the 1980s; as research activities increased during the 1980s, interest in fusing them has also been rapidly increasing, and these cooperative technologies have widely and practically spread into commercial products and industrial systems during the 1990s [1]. Roughly speaking, 1980s was the decade of each computational intelligence technology, and 1990s was the decade of the cooperative technologies of computational intelligence technologies.

What comes next? There are several directions where computational intelligence research could go from now. One of possible research directions would be a humanized technology where computational intelligence technologies and humans are cooperatively combined similar to the research on human factors or KANSEI in the 1990s (see Figure 1). One of the realized ways of the humanized technology is the IEC that combines the human evaluation capability with the computer optimization capability.

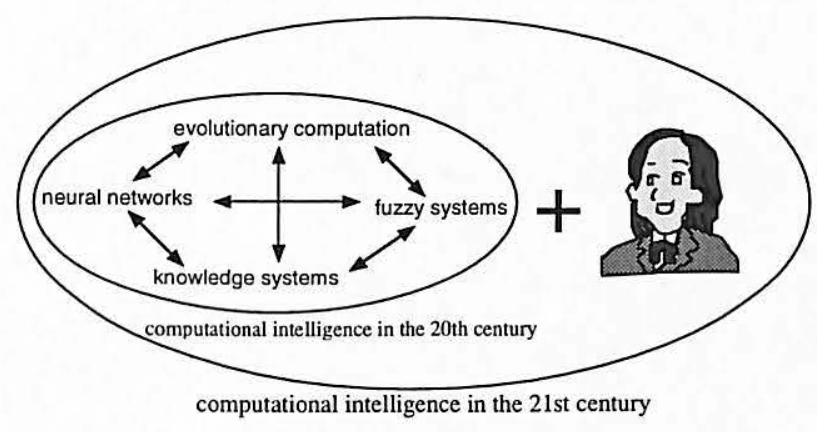

Figure 1: Computational Intelligence (CI) research from now.

\section{Interactive Evolutionary Computation as Humanized Technology}

The IEC is an EC that optimizes systems based on subjective human evaluation. The IEC will become more important in design, adjustment, and creation that are directly related with human essential $K A N$ $S E I$ factors such as preference, emotion, feeling, and so on. It is deeply expected that as the IEC is further developed, it will help unite humanized technology with user-friendly technology.

Even classic engineering technologies which did not seem to need human factors are requested to be humanized technologies, and the IEC can make the conventional technologies be humanized technologies. Let us see such examples. Intelligent robotics can measure physical environment of a robot, avoid obstacles, and control the speed and direction of the robot. But, it cannot realize preferred or gentlemannered robot actions without human evaluation. Conventional AI tools can acquire knowledge from a database but cannot obtain qualified knowledge without expert's evaluation of the acquired knowledge. It is easy for image or sound signal processing to design a filter to maximize signal-noise ratio, the conventional signal processing cannot match the processes images or sounds with human preference without the human. 
Table 1: Statistics of IEC papers by field and year. Papers that discuss more than one topic are counted in each corresponding category.

\begin{tabular}{|c|c|c|c|c|c|c|c|c|c|c|c|c|c|}
\hline & $80 \mathrm{~s}$ & 90 & '91 & 92 & 93 & 94 & 95 & 96 & 97 & 98 & '99 & 2000 & total \\
\hline graphic art \& CG animation & 2 & & $\overline{3}$ & $\overline{2}$ & 4 & 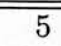 & 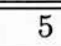 & 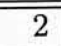 & 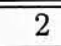 & 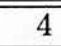 & 9 & $\overline{44}$ & 442 \\
\hline 3-D CG lighting design & & & & & & & & 1 & 3 & 1 & & & 5 \\
\hline music & & & & & 1 & 3 & 3 & 1 & & 1 & 3 & 5 & 17 \\
\hline editorial design & & & & & & & & & 1 & & 1 & 2 & 4 \\
\hline industrial design & & & & 2 & 2 & 1 & 5 & 4 & & 2 & 4 & 9 & 29 \\
\hline face image generation & & & 1 & & 1 & 1 & 2 & & 1 & 4 & 5 & 1 & 16 \\
\hline speech processing \& prosodic control & & & & & & & 2 & 1 & 2 & & 1 & 1 & 7 \\
\hline hearing aids fitting & & & & & & & & & & 2 & 7 & 5 & 14 \\
\hline virtual reality & & & & & & & & 1 & 1 & & & & 2 \\
\hline database retrieval & & & & & & & & 2 & 1 & 8 & 8 & 1 & 20 \\
\hline knowledge acquisition \& data mining & & & & & & & 5 & 3 & 3 & 1 & 4 & & 16 \\
\hline image processing & & & & & & & & & 1 & 2 & & & 3 \\
\hline control \& robotics & & & & 1 & & & & 2 & & 3 & 4 & 4 & 14 \\
\hline Internet & & & & & & & & & & 1 & 2 & 1 & 4 \\
\hline food industry & & & & & & & & 1 & 1 & & & & 2 \\
\hline geophysics & & & & & & & & & & & 1 & 2 & 3 \\
\hline art education & & & & & & & & & & & & 2 & 2 \\
\hline writing education & & & & & & & & & 1 & 3 & & & 4 \\
\hline games and therapy & & & & & & & & 1 & 1 & 1 & & & 3 \\
\hline social system & & & & & & & & & & 1 & & & 1 \\
\hline discrete fitness value input method & & & & & & & & 5 & & 2 & & & 7 \\
\hline prediction of fitness values & & & & & & & 1 & 2 & 1 & 8 & 3 & 1 & 16 \\
\hline interface for dynamic tasks & & & & & & 1 & & & & & 1 & 3 & 5 \\
\hline acceleration of EC convergence & & & & & & & & 1 & 1 & 3 & 1 & & 7 \\
\hline combination of IEC and non-IEC & & & & & & & & 1 & 2 & & & & 3 \\
\hline active intervention & & & 1 & & & & & & & & 3 & 2 & 6 \\
\hline total & 2 & 0 & 5 & 5 & 8 & 11 & 23 & 28 & 22 & 48 & 57 & 43 & 252 \\
\hline
\end{tabular}

\section{Wide VARIETy OF IEC RESEARCH}

Many papers on IEC research have been published in various fields for these 10 years [2]. There are two main research directions of IEC applications and IEC interface research.

The IEC application fields include graphic arts and animation, 3-D CG lighting, music, editorial design, industrial design, facial image generation, speech processing and synthesis, hearing aid fitting, virtual reality, media database retrieval, data mining, image processing, control and robotics, food industry, geophysics, education, entertainment, social system, and so on.

The interface research to reduce human fatigue includes improving fitness input interfaces and displays based on fitness prediction, accelerating EC convergence especially in early EC generations, examining combinations of interactive and normal EC, and investigating active user intervention.

Table 1 shows these wide varieties of the IEC research by year.

\section{Conclusion}

In this abstract paper, we try to show what research direction of computational intelligence becomes important from now and why. Humanized technology is our answer to its question, and the IEC is one of our concrete realization ways of the humanized technology.

\section{REFERENCES}

[1] Hideyuki Takagi, "Fusion Technology of Neural Networks and Fuzzy Systems: A Chronicled Progression from the Laboratory to Our Daily Lives," International Journal of Applied Mathematics and Computer Science, Vol.10, No.4, pp.647-673 (2000).

[2] Hideyuki Takagi, "Interactive Evolutionary Computation: Fusion of the Capacities of EC Optimization and Human Evaluation," Proceedings of the IEEE (will appear in 2001). 